\title{
Echinococcus multilocularis inoculation induces NK cell functional decrease through high expression of NKG2A in C57BL/6 mice
}

Abuduaini Abulizi ${ }^{1 \dagger}$, Yingmei Shao ${ }^{1,2 \dagger}$, Tuerganaili Aji ${ }^{1,2}$, Zhide $\mathrm{Li}^{1}$, Chuanshan Zhang ${ }^{2,3}$, Abudusalamu Aini ${ }^{1}$, Hui Wang ${ }^{2,3}$, Tuerhongjiang Tuxun ${ }^{4}$, Liang Li ${ }^{2,3}$, Ning Zhang ${ }^{1}$, Renyong Lin ${ }^{2,3}$ and Hao Wen ${ }^{1,2,3^{*}}$

\begin{abstract}
Background: Alveolar echinococcosis (AE) is caused by the larval stage of Echinococcus multilocularis (E. multilocularis), and considered as public health issue. Parasite-host immune interaction is pivotal during infection. As a subset of innate lymphoid cells, NK cells are known to play an important role during virus, bacteria, intra/ extracellular parasitic infections and tumor progression. However, the possible role of NK cells in E. multilocularis infection in both human and murine is little known. Herein, the functional alteration of hepatic NK cells and their related molecules in E. multilocularis infected mice were studied.

Methods: 2000 protoscoleces (PSCs) were injected to C57BL/6 mice via the portal vein to establish secondary E. multilocularis infection. NK cells population and their related molecules (CD69, Ly49D, Ly49G2, Ly49H, Ly491, NKG2A, NKG2D, granzyme B, IFN- $\gamma$, TNF-a) were assessed by using fluorescence-activated cell sorter (FACS) techniques and qRT-PCR. NK cell depletion was performed for further understanding the possible function of NK cells during infection.

Results: The total frequencies of NK cells and NK-derived IFN- $\gamma$ production were significantly reduced at designated time points $\left(2,4,12\right.$ weeks). The liver resident $\left(C D 49 a^{+} D X 5^{-}\right)$NK cells are decreased at 4 weeks after inoculation and which is significantly lower than in control mice. Moreover, in vivo antibody-mediated NK cell depletion increased parasitic load and decreased peri-parasitic fibrosis. Expression of the inhibitory receptor NKG2A was negatively related to NK- derived IFN- $\gamma$ secretion.

Conclusions: Our study showed down regulates of NK cells and upper regulates of NKG2A expression on NK cells during E. multilocularis infection. Reduction of NK cell frequencies and increased NKG2A might result in low cytotoxic activity through decreased IFN- $\gamma$ secretion in E. multilocularis infection. This result might be helpful to restore NK cell related immunity against $E$. multilocularis infection to treat alveolar echinococcosis.
\end{abstract}

Keywords: Echinococcus multilocularis, NK cells, NKG2A, Immune tolerance

\footnotetext{
* Correspondence: dr.wenhao@163.com

${ }^{+}$Abuduaini Abulizi and Yingmei Shao contributed equally to this work.

'State Key Laboratory of Pathogenesis, Prevention and Treatment of High

Incidence Diseases in Central Asia, Hepatobiliary \& Hydatid Disease

Department, Digestive \& Vascular Surgery Center, First Affiliated Hospital of

Xinjiang Medical University, Urumqi 830054, China

${ }^{2}$ WHO Collaborating Center on Prevention and Management of

Echinococcosis, First Affiliated Hospital of Xinjiang Medical University, Urumqi

830054, China

Full list of author information is available at the end of the article
}

(c) The Author(s). 2019 Open Access This article is distributed under the terms of the Creative Commons Attribution 4.0 International License (http://creativecommons.org/licenses/by/4.0/), which permits unrestricted use, distribution, and

reproduction in any medium, provided you give appropriate credit to the original author(s) and the source, provide a link to the Creative Commons license, and indicate if changes were made. The Creative Commons Public Domain Dedication waiver (http://creativecommons.org/publicdomain/zero/1.0/) applies to the data made available in this article, unless otherwise stated. 


\section{Background}

Alveolar echinococcosis, caused by the larval stage of $E$. multilocularis, continues to be a real world-wide public health issue. It is prevalent mainly in Western China, Middle East and as well as Central Europe [1]. China harbors nearly $90 \%$ of economic burden of $\mathrm{AE}$ around the world and thus sustained efforts have been made on prevention, control and management of this disease [2]. E. multilocularis infection predominantly target itself in the host's liver and reside itself with incoming infiltrative growth and consequently lead to the critical involvement of vasculature [3]. Although, tremendous improvement has been made in the field of hepatic surgery including radical resection, liver transplantation and ex vivo liver resection and autotransplantation with promising clinical outcome [3]. Of note, nearly $90 \%$ mortality rate was reported within 10 15 years after initial diagnosis if untreated or insufficiently treated [4-6]. The attempt to unveil the underlined mechanism of such an infiltrative disease, regarded as "parasitic cancer", is vital important.

To date, $\mathrm{AE}$ is considered as immune related parasitic infection with very intriguing and diversified immune cross-talk between host and parasite depending on the stage of the disease [7]. It is reported the E. multilocularis infection modulate Th cell subsets to maintain a high Th1 in early stage while Th2 dominant immune profile in both peripheral and regional milieu [8]. Our recent studies have demonstrated the potential importance of the remaining Th subsets such as Th17 [9], Treg [10] and Th9 [11] in E. multilocularis infection. Besides, our data indicated T-cell tolerance and exhaustion during clearance of E. multilocularis [12]. CD4 ${ }^{+} \mathrm{T}$ and $\mathrm{CD}^{+} \mathrm{T}$ cells present the major source of $\mathrm{T}$ cells in early and late stage of $E$. multilocularis infection, respectively [13]. Other studies indicate that the early infective stage of E. multilocularis is a strong inducer of tolerance in dendritic cells (DCs) [14], and the proliferative potential of the parasite metacestode tissue is dependent on the peri-parasitic immune-mediated processes of the host [7].

The both adaptive and innated immunity is pivotal importance to the parasite infection [15]. As an active member of innate immunity, NK cells compose approximately $20-30 \%$ of liver-resident lymphocytes with the far lower percentage in peripheral blood [16]. The contact-dependent signals provided by DCs, monocyte/macrophages, $\mathrm{CD} 4^{+} \mathrm{T}$ cells as well as secreted cytokines activate NK cells during various infections [17]. It causes death of virus-infected cells $[18,19]$, tumor cells [20], and limit the progression of intracellular and extracellular parasites [21-25]. It is also reported that, the liver fibrosis and carcinogenesis formation process is hugely limited in the presence of NK cells in hepatitis [26]. Preliminary data showed the inhibited activation and proliferation of NK cells in E. multilocularis vesicular fluid co-culture and indicated its possible role in tolerative pathogen-host interaction [27].

Although, a plenty of work has been done in the field of immune interaction in E. multilocularis infection, however, very few is known regarding the possible role of innate immunity, especially NK cells in E. multilocularis infection. Herein, we are aiming to explore the expression of NK cells and its relative molecules, its potential impact on the disease progression, if any, in murine model of portal vein inoculation of $E$. multilocularis.

\section{Methods}

\section{Animal model and infection}

Eight-to-ten weeks old C57BL/6 female mice (Beijing Vital River Experimental Animal Technology Co. Ltd.), raised with standard feed and water in sterilized fiftyfifty light/dark altered condition, were used as animal model for E. multilocularis protoscoleces (PSCs) infection. PSCs, which was intraperitoneally carried within lesions in BALB/c mice prior to acquisition, was cleaned-up for several times by phosphate buffered saline (PBS, $\mathrm{pH}=7.2$, containing $1000 \mathrm{mg} / \mathrm{mL}$ penicillin and $1000 \mathrm{U} / \mathrm{mL}$ streptomycin) to prepare an injectable and sterilized suspension. The number of PSCs in the suspension was counted (using a DMI 4000B microscope, Leica, Germany), and) and adjusted by sampling three times to proper PSCs concentration in EP tubes before injection. Mice were anesthetized by $2.5 \%$ chloral hydrate and each mouse injected $0.1 \sim 0.15 \mathrm{ml}$ into the abdominal cavity. Mice were inoculated via the hepatic portal vein with 2000 doses of PSCs in saline, whereas control mice were injected with isotonic saline. All mice received 200-300 $\mu \mathrm{l}$ of E. multilocularis PSCs sediment via the hepatic portal vein by using a $0.45 \times 15$ RWLB venous infusion needle [12]. Mice were sacrificed at every experimental timepoints $(2,4,12$, 24 weeks after model was established) using euthanasia, which was approved by Institutional Animal Care and Use Committee. Specifically, mice were intraperitoneally (left lower quadrant) injected with $5 \%$ chloral hydrate $0.15-$ $0.20 \mathrm{ml} /$ mouse through medical syringe needle, and peripheral blood was collected by retro-orbital bleeding after successfully anesthetized; then, whole liver samples were obtained surgically; at last, mice were euthanized using cervical dislocation; the dead body further packed with special medical waste bags to freeze under $-20^{\circ} \mathrm{C}$ and delivered for biosafety handling. Cysts were established at least 4 weeks after multilocularis inoculation, infections were confirmed based on both gross specimen observations and microscopic evaluation when the mice were sacrificed, and parasitic load in the livers were 
determined using cyst or lesion scales measured when liver specimens were obtained. That week number 2-4, 4-12 and 12-24 were respectively divided as pre-, intra-, and post-encystment phases in our team's previous publication [12] that used same methodology. We designated these phases: 2 weeks after inoculation as pre-encystment timepoint (early stage); 4 and 12 weeks after inoculation as intra-encystment timepoints (middle stage); 24 weeks after inoculation as post-encystment timepoint (late stage).

\section{Flowcytometry analysis}

Hepatic monocular lymphocytes were isolated as described [28]. For flowcytometry, after incubation with Fc-receptor blockage for $15 \mathrm{~min}$ at $4{ }^{\circ} \mathrm{C}$, NK1.1, CD3, CD69, CD27, CD11b, CD49a, DX5, Ly49D, Ly49G2, Ly49H, Ly49I, NKG2A, NKG2D, granzyme $\mathrm{B}$, IFN- $\gamma$, TNF- $\alpha$ molecules were marked with relevant antibodies according manufactory protocols (Additional file 1: Table S1) in order to analysis of some inhibitory/activating molecules and cytokines dynamics on NK cells. Moreover, as for intracellular cytokine marking, approximately $1 \times 10^{\wedge} 6$ monocular lymphocytes were stimulated using Cell Stimulation Cocktail for $4 \mathrm{~h}$ [28]. IgG isotype controls were used as parallels. At last, we applied ALSRFortessa flow cytometry platform and Flowjo Software to analyze output data.

\section{Quantitative real-time PCR (qRT-PCR) analysis}

Quantitative RT-PCR was used for analysis the mRNA levels of CD69, NKG2A, NKG2D, Ly49G2, Ly49I, Ly49D, Ly49H in whole-liver tissue at designated timepoints after infection with $E$. multilocularis and normalized by comparison to GAPDH.

Total RNA, extracted from the liver using Trizol Reagent (Invitrogen, Canada), was reversed using M-MLV transcriptase according to manufactures' instructions (Thermo, USA), then qRT-PCR (see primer information in Table 1) was implemented in thermocycler (iQ5 BioRad, Canada) with SYBR Green PCR premix (TaKaRa,
China) [29]. The results were calculated by the $2^{-\Delta \Delta C t}$ method.

\section{NK cell depletion in vivo}

NK cells were depleted by administering $150 \mu \mathrm{g}$ antiNK1.1 (clone PK136, BioXCell) or control (PBS) via intraperitoneal injection three times a week, which started on 12th week after E. multilocularis PSCs inoculation. The efficacy of NK cells depletion was verified by flowcytometry of PBMC after depletion.

\section{Routine histopathological observation and collagen staining}

Peri-foci histopathological changes were evaluated in three different levels: (a) inflammatory foci: accumulation of inflammatory cells to form small foci, but free of parasite, visible PSCs or metacestodes; (b) inflammatory foci with fibrosis: fibrotic tissue formation on the basis of (a); (c) infectious foci with germinal layer: accumulation of inflammatory cells and fibrosis with obvious germinal layer of the parasite [12]. Infection status was assessed by the percentage of above three levels' quantity within the liver. Peri-foci fibrosis determined by picric acid-sirius red staining and immunohistochemical staining for $\alpha$-SMA for detection of activated hepatic stellate cells (HSCs) (original magnification $\times 100$ ). The percentage of positive staining areas and cells was calculated using cellSens Dimension software (Olympus, Tokyo, Japan).

\section{Statistical analysis}

Statistical analysis was performed using GraphPad Prism 7.0 (GraphPad Software, San Diego, CA). Tow-way ANOVA test with a Tukey's multiple comparison was used when there were more than two groups. Sample size: $3-5$ mice per group. $P<0.05$ was considered statistically significant. $\left(P\right.$-values were presented as: ${ }^{*} P<$ 0.05 ; ${ }^{* *} P<0.01$; ${ }^{* * *} P<0.001$; ${ }^{* * * * *} P<0.0001$ ).

Table 1 Sequences of the qRT-PCR primers

\begin{tabular}{lll}
\hline Gene & Forward primer & Reverse primer \\
\hline CD69 & TGGTCCTCATCACGTCCTTAATAA & TCCAACTTCTCGTACAAGCCTG \\
NKG2A & TCAGCACAGCCTTGCCTC & CTTCTTCCAGACCCAGGGC \\
NKG2D & CCAATGTTCGTTTTCGAGTCC & GCACAATACTGGCTGAAACGTC \\
Ly49G2 & TGCCACGATAACTGCAGCC & ATGGGTCTTTGTGAACACCTG \\
Ly49I & GGAACAGTGAAACCAAGACGG & CTGTAATGCTGGCAGTTCGC \\
Ly49D & TCAGGGTTGCAGAACGAGATGAG & AGGATCCCGAGAGCTATCACAATG \\
Ly49H & TGGGACAGTGAAACCAAGAGTG & GCTGTAATGCTGGCAGTTCG \\
GAPDH & CACTCACGGCAAATTCAACGGCAC & GACTCCACGACATACTCAGCAC \\
\hline
\end{tabular}




\section{Results}

NK cells population is markedly decreased in infected mice

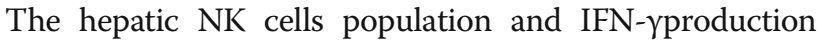
were decreased respectively at 2, 4, 12 weeks post $E$. multilocularis inoculation, but at 24th week after infection no change was observed (Fig. 1a, b, c, d), while TNF- $\alpha$ and granzyme B levels had no significance in designated time points (Additional file 2: Figure S1). The percentage of liver resident $\mathrm{CD} 49 \mathrm{a}^{+} \mathrm{DX} 5^{-} \mathrm{NK}$ cells gradually decreased at 4 weeks after E. multilocularis infection (Fig. 1e, f). It is currently known, NK cells move through four distinct maturation steps marked by changes in expression of CD27 and CD11b [30]. Given that background, we

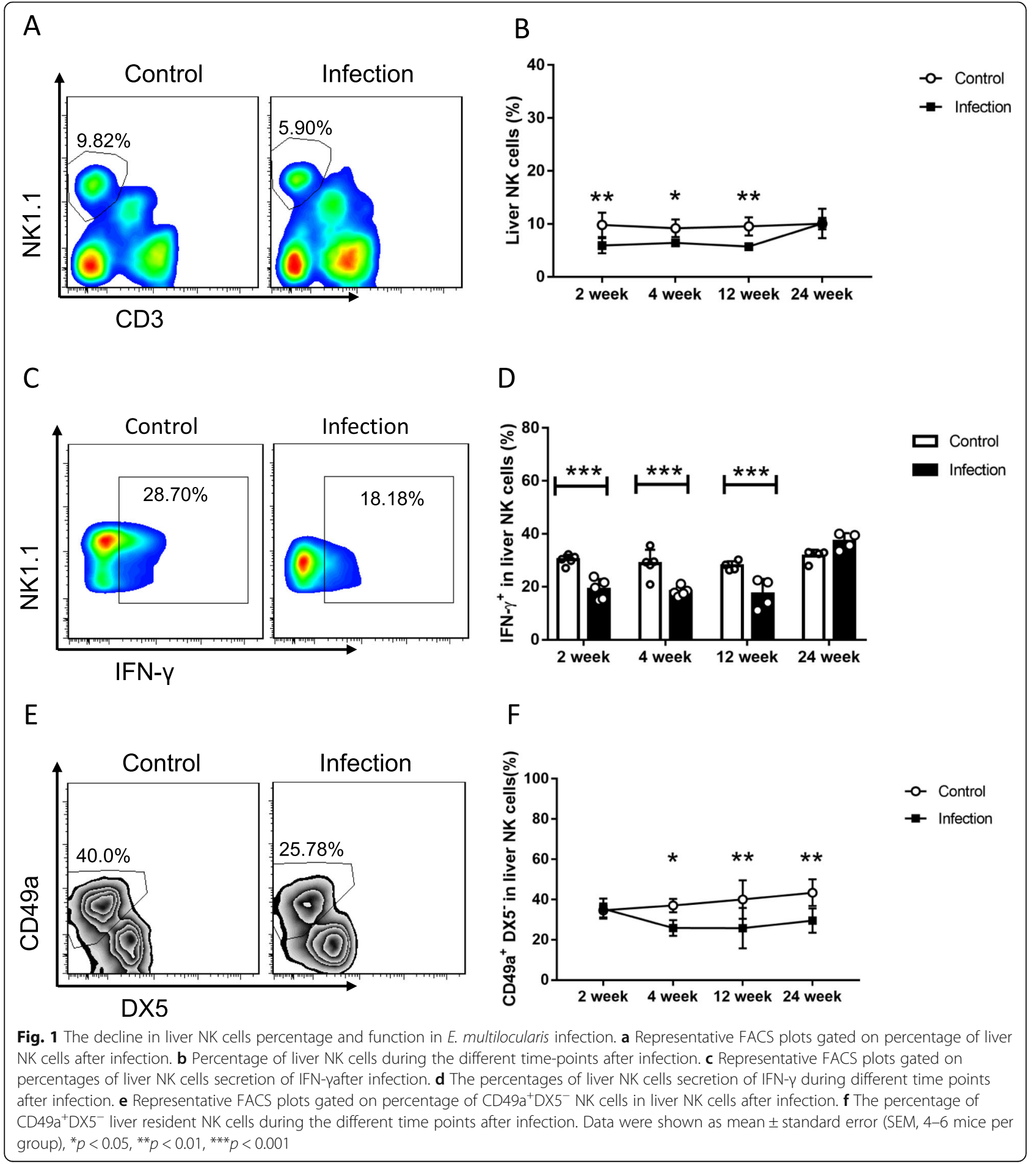


observed CD27 and CD11b changes in order to determine whether the reduction of NK cells population was due to maturation dynamics or activation process. Our results showed that, NK cells transformed from an immature form $\left(\mathrm{CD} 27^{-} \mathrm{CD}^{-11 b^{-}}\right.$, stage 1$)$ into mature or older forms $\left(\mathrm{CD} 27^{-} \mathrm{CD} 11 \mathrm{~b}^{+}\right.$, stage 4$)$ during E. multilocularis infection (Fig. 2a). Further, the most functional subtype $\mathrm{CD} 27^{+} \mathrm{CD} 11 \mathrm{~b}^{+}$(stage 3 ) comparatively decreased at early stages (2, 4 weeks), while increased at middle and late stages (12, 24 weeks) after infection (Fig. 2b). Besides, during the whole process, CD69-positive NK cells ratio was elevated compared to control mice (Fig. 2c, d). Theses above results illustrated that $E$. multilocularis infection can modulate both hepatic NK cells population and its' IFN-yproduction processes.

\section{NK cell depletion in vivo exacerbated E. multilocularis infection}

To clarify NK cells' overall functional role, in vivo antibody mediated NK cell depletion was performed. The intrahepatic parasitic load was increased when NK cell was depleted (Fig. 3a, b, c, d). Specifically, the percentage of inflammatory foci and infectious foci with metacestode structures were higher than control mice (Fig. 3e, f, h). Peri-lesion (infected foci) collagen deposition, assessed by Sirius Red Staining and immunohistochemical staining for $\alpha$-SMA for detection of activated hepatic stellate cells, revealed obvious reduction of peri-parasitic fibrosis and increase of intrahepatic parasitic load in NK cell-depleted mice (Fig. 4). These results suggested that, NK cell depletion might have downregulated cytotoxic activity of immune cells in peri-lesion microenvironment and fibrotic structure formation, which together helped with the pathogen to easily progress in the liver and to upgrade lesion load. However, it's still unclear that what molecule or mechanism led theses changes in NK cells.

\section{Alteration of both activating and inhibitory NK cell receptors in infected mice}

NK cells' target recognition, immune response and tolerance are mainly mediated through cell surface receptors, including activating and inhibitory receptors [31]. To
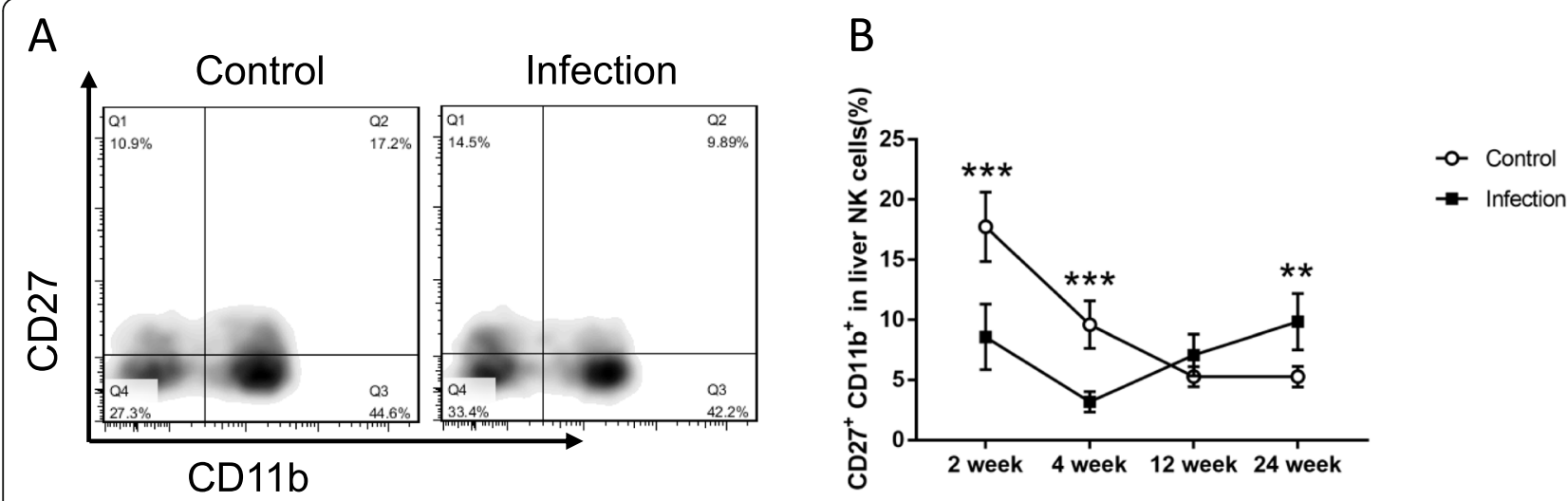

C
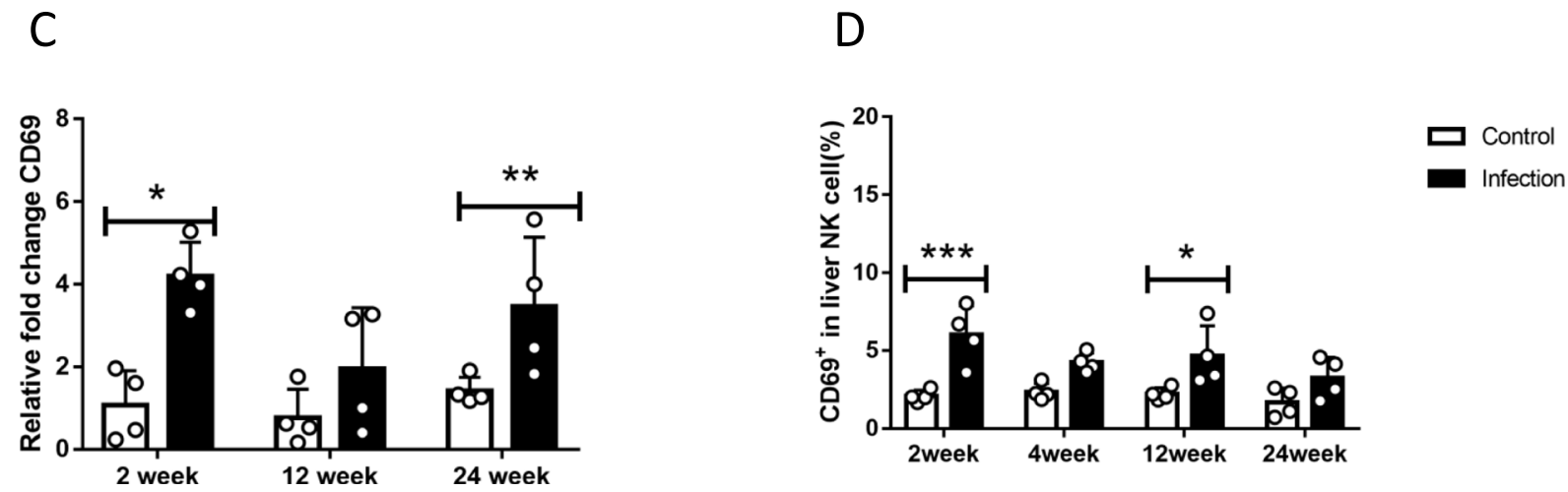

Fig. 2 The maturation status and activation of mice liver NK cells in E. multilocularis infection. a Representative FACS plots gated on percentage of $C D 27^{+} C D 11 b^{+}$NK cells in liver NK cells at 2 weeks after infection. $\mathbf{b}$ Percentage of mature $C D 27^{+} C D 11 b^{+}$in liver NK cells at different time points after infection. c QRT-PCR analysis for mRNA levels of receptor CD69 in whole-liver tissue at various time points after infection and normalized by comparison to GAPDH mRNA. d Percentage of $\mathrm{CD}_{6} 9^{+} \mathrm{NK}$ cells in liver at different time points after infection. Data were shown as mean \pm standard error (SEM, 4-5 mice per group), ${ }^{*} p<0.05 ;{ }^{* *} p<0.01 ;{ }^{* *} p<0.001 ;{ }^{* * *} p<0.0001$ 


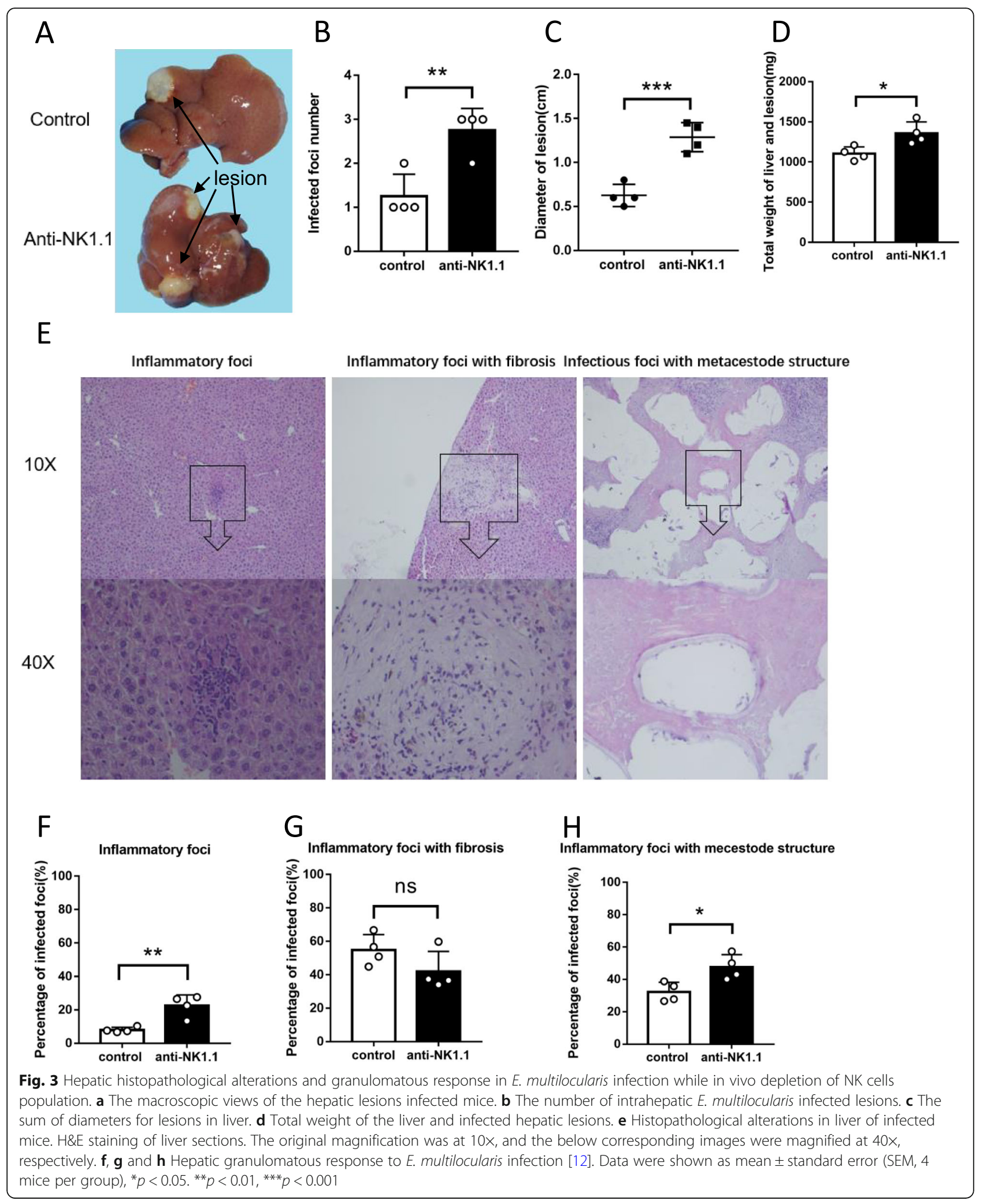

investigate whether the receptor alterations affected those changes above, FACS analysis was performed mainly focusing on known surface markers. Relevant data indicated that, expression of inhibitory receptor NKG2A on NK cells was significantly higher at designated time points than control mice (Fig. 5a, b, c), while 

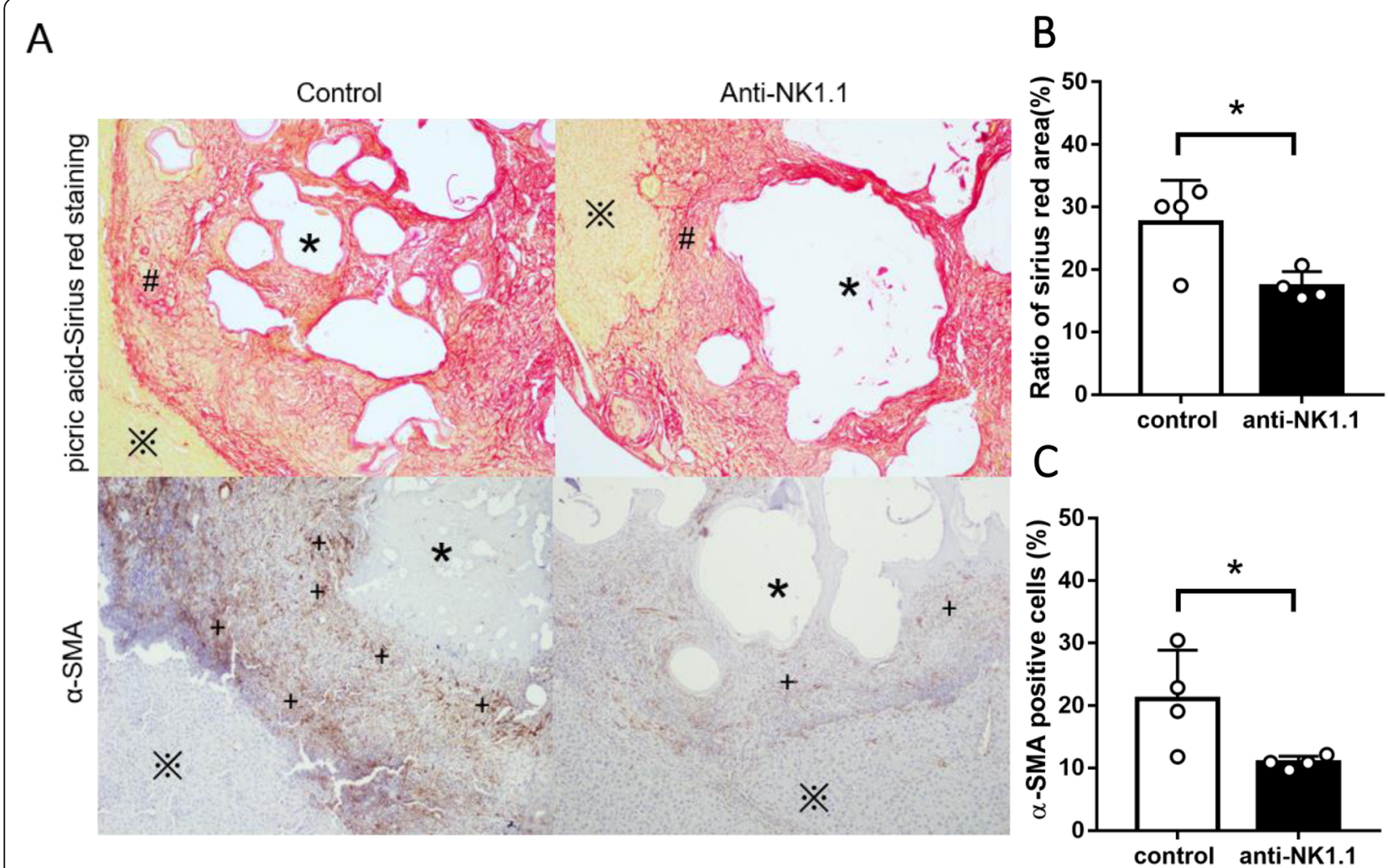

Fig. 4 The peri-parasitic fibrosis in E. multilocularis infected mice while in vivo depletion of NK cells population. a The peri-parasitic fibrosis of hepatic lesion was determined by picric acid-Sirius red staining (the red area represents fibrillar collagen) and immunohistochemical staining for a-SMA (detection of activated hepatic stellate cells) (original magnification $\times 100$ ). $\mathbf{b}$ The peri-parasitic fibrosis area of the section was quantified using cellSens Dimension software, the ratio of collagen area and total area (\%) was counted. $\mathbf{c}$ The percentage of positive staining cells in periparasitic area was calculated using cellSens Dimension software to assess the expression of a-SMA on the lesion around areas. Lesion (*), liver tissue $(※)$, peri-parasitic fibrosis area (\#), activated hepatic stellate cells (+). (Data were shown as mean \pm standard error (SEM, 4 mice per group), ${ }^{*} p<0.05$

activating receptor NKG2D was only elevated at early stages (2, 4 weeks) post E. multilocularis infection (Fig. 5d, e, f), and similar findings on some other receptors also had no obvious alterations (Additional file 3: Figure S2A, B, C, D). It can be inferred from the scenario that NK cells' numeric and functional changes might be related to cell surface inhibitory receptor NKG2A molecule dynamics.

\section{NKG $2 \mathrm{~A}^{+}$NK cell population in infected mice showed impaired cytokine production}

Activated NK cells mediates protection against pathogens, which is characterized through secretion of cytokines, primarily IFN- $\gamma$ [32]. For the next step, both $\mathrm{NKG}_{2} \mathrm{~A}^{+} \mathrm{NK}$ and NKG2D ${ }^{+}$NK cells were studied for functional analysis to estimate the cytokine production in E. multilocularis infection, intracellular cytokines were stained using FACS techniques (Fig. 6). It can be revealed that, NKG2A ${ }^{+}$NK cells' IFN-ysecretion was significantly lower than control group, however, which had no obvious change in NKG2D ${ }^{+}$NK cells, and some other cytokines did the same way (Additional file 4: Figure S3). So far, we were able to demonstrate that $\mathrm{NKG}_{2} \mathrm{~A}^{+} \mathrm{NK}$ cell population showed impaired cytokine production in E. multilocularis infected mice.

\section{Discussion}

Our results demonstrated the profound decrease of liver NK cells population but sharp increase of NKG2A expression in E. multilocularis infected mice. Such alteration might result in low cytotoxic activity through decreased IFN- $\gamma$ secretion, as well as the disease progression with its potentiality in the immune tolerance milieu in infected liver. To the best of our knowledge, this is the first report on hepatic NK cells and their related molecules in murine model of $E$. multilocularis infection.

NK cells play significant role against intracellular viruses and bacteria, tumors, protozoa, parasites infection [33]. Immune tolerance due to compromised NK cells' cytotoxic activity has been frequently observed both in experimental and human study with tumor and 


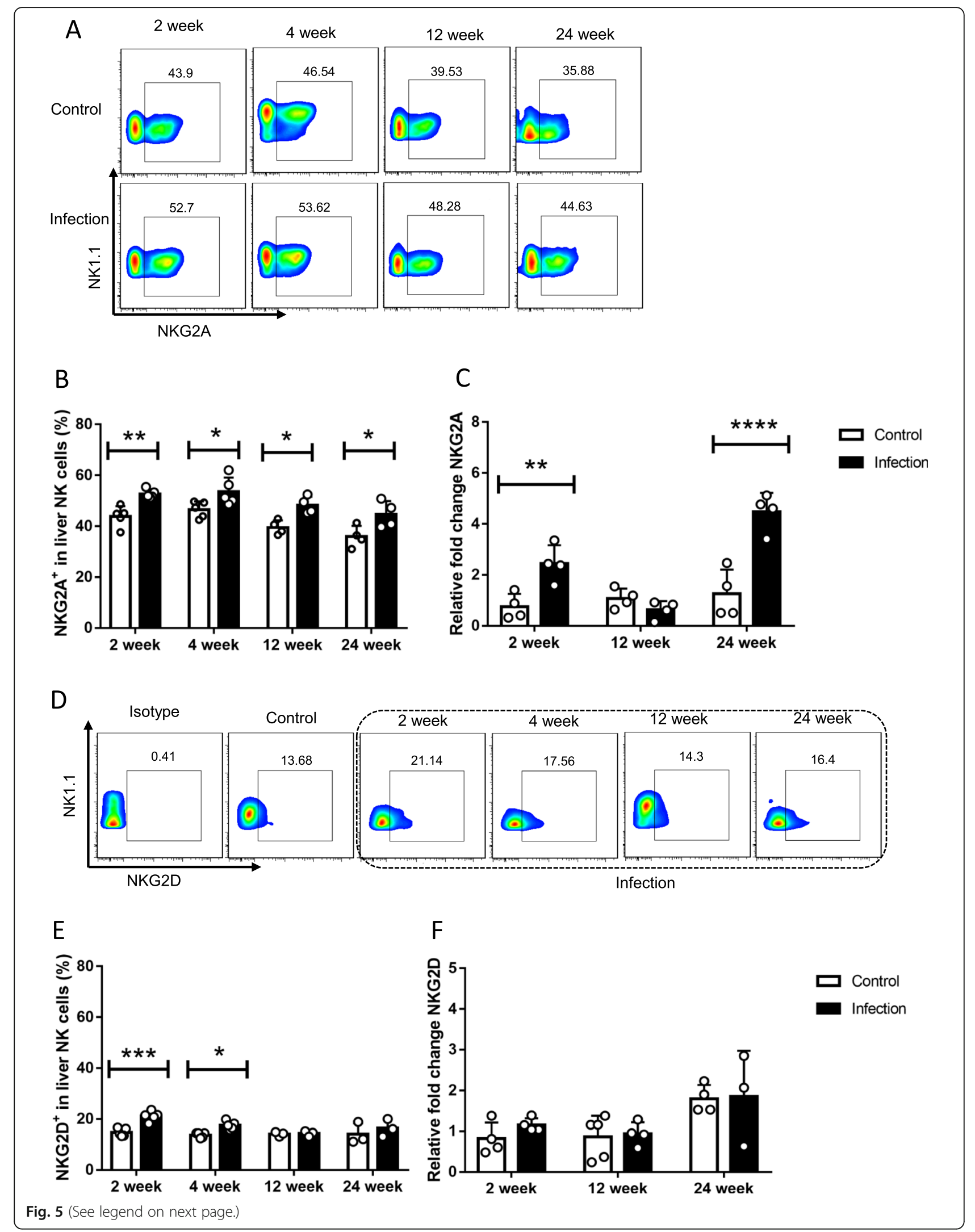


(See figure on previous page.)

Fig. 5 The expression of NKG2A and NKG2D on the hepatic NK cells in E. multilocularis infection. a Representative FACS plots gated on

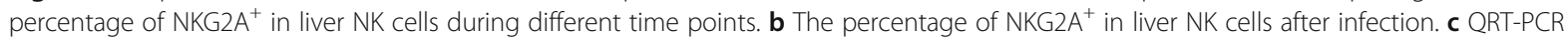
analysis for mRNA levels of receptor NKG2A in whole liver tissue at various time points after infection and normalized by comparison to the

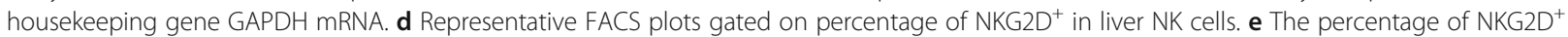
in liver NK cells after infection. $\mathbf{f}$ QRT-PCR analysis for mRNA levels of receptor NKG2D in whole liver tissue at various time points after infection and normalized by comparison to the housekeeping gene GAPDH mRNA. Data were shown as mean \pm standard error (SEM, 3-5 mice per group). ${ }^{*} p<0.05 ;{ }^{* *} p<0.01 ;{ }^{* * *} p<0.001,{ }^{* * *} p<0.0001$

chronic infection [31, 34]. Since NK cell population play a key role in the process of tumor and chronic infection development, many recent studies support the importance of NK cells during parasitic infection. Toxoplasma gondii infection impairs NK cell recognition of target cells and cytokine release, then independently enhances its survival [35]. NK cells can limit malaria infection by producing IFN- $\gamma$ and killing infected cells before being superseded by the adaptive immune response [22] Moreover, reduction of NK cell numbers and impaired NK cells response observed in patients with acute cutaneous leishmaniasis [36]. NK cells population and its function changed in Angiostrongylus cantonensis infected mice, suggesting their involvement in pathogenesis of the infection [24]. Activated NK cells is reported to negatively regulate egg-induced liver fibrosis via producing IFN- $\gamma$, and killing activated stellate cells in Schistosoma japonicum infection [25]. Like other metacestode infection, $\mathrm{AE}$ is featured by chronic granuloses formation and present various immunopathological processes. Available data showed inhibited activation of NK cells after co-culture with $E$. multilocularis vesicular [27]. Human study demonstrated decreased NK cells frequency in peripheral blood in AE patients and concluded the possible involvement of NK cells during $\mathrm{AE}$ infection [37]. Herein, our results displayed decrease in NK cell percentage and IFN- $\gamma$ production in hepatic tissue of E. multilocularis infected mice. It is known that $\mathrm{CD} 49 \mathrm{a}^{+} \mathrm{DX} 5^{-}$and $\mathrm{CD} 49 \mathrm{a}^{-} \mathrm{DX} 5^{+}$are the two major hepatic NK subsets. $\mathrm{CD}_{4} 9 \mathrm{a}^{+} \mathrm{DX} 5^{-}$NK cells is liver resident NK cells and possesses memory potential [38].
In current study, lower percentage of $\mathrm{CD} 49 \mathrm{a}^{+} \mathrm{DX} 5^{-} \mathrm{NK}$ cells were observed in infected liver. And most intriguingly, significant increase of parasite load but decrease of peri-parasitic fibrosis was also observed after the depletion of NK cells.

Commonly, the ingestion of E. multilocularis metacestode initiate cross-talk with the host's immune system and induces recruitment and infiltration of various immune cell types. The fibrotic layer, secondary to the immune response, successfully separates the parasite and limits its growth $[39,40]$. In the context of NK cell depletion, the process of cross-talk is not "smooth" and lead the continuous growth of the parasite and failure of limitation by fibrotic tissues. Besides, the over expression of TGF- $\beta$ [40], and IL-10 [41] after E. multilocularis infection might contribute to NK cell inhibition, resulting into NK cell activating receptors' imbalance, consequently reducing IFN- $\gamma$ secretion and impairing the NK cell immune surveillance.

NK cell function is tightly regulated by activating and inhibitory molecules [33]. Either the downregulation of activating receptors such as NKG2D, NKp30, NKp46, or upregulation of inhibitory receptors like Tim-3, NKG2A, PD-1 lead to NK cell dysfunction [26]. Upregulation of NKG2A in chronic HBV and $\mathrm{HCV}$ infection is purportedly associated with NK cell exhaustion $[42,43]$. NKG2A ${ }^{\text {high }}$ status contributes to NK cell exhaustion and predicts poor prognosis in liver cancer patients [12]. In addition, newest research demonstrated that anti-NKG2A mouse antibody is an immune checkpoint inhibitor that promotes anti-
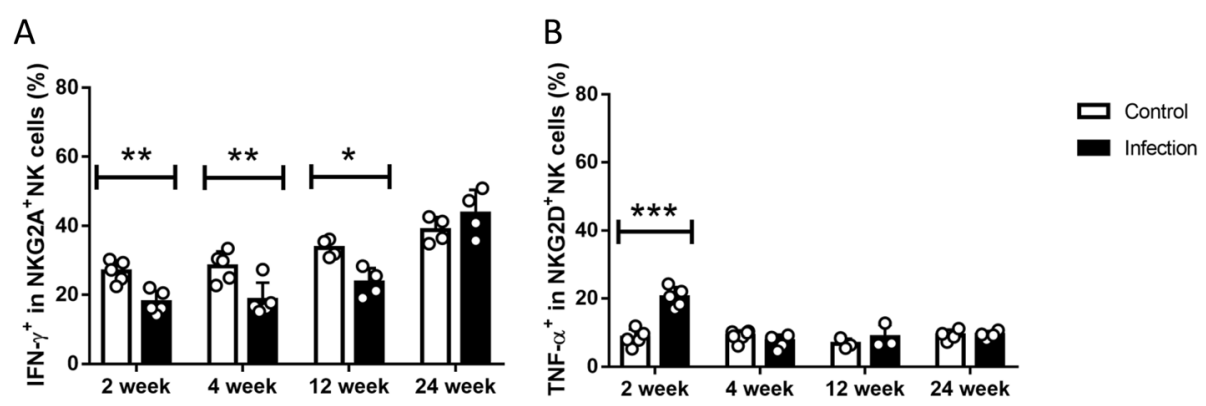

Fig. 6 Cytokine production of NKG2A+ NK and NKG2D+ NK cells in E. multilocularis infection. a Percentage of IFN-yproduced by liver NKG2A+ NK cells during the different time points after infection. $\mathbf{b}$ Percentage of TNF-a produced by liver NKG2D+ NK cells during the different time points after infection. Data were shown as mean \pm standard error (SEM, 3-5 mice per group), ${ }^{*} p$ values $<0.05,{ }^{* *} p<0.01$ and ${ }^{* * *} p<0.001$ 
tumor immunity by unleashing both $\mathrm{T}$ and NK cells [44] . In this study, our result showed that NKG2A is upregulated at all designated time points in experimental $E$. multilocularis infection. Such change is related with decreased numeric and functional NK cells at early and middle stages, and it might be responsible for the increased parasite load and extensive infection. However, at the late stage, NK cells' functional decrease has been reversed, which may be related to server $\mathrm{T}$ cell exhaustion led to upregulation of other activated molecules on NK cells in very late stage of infection. Thus, further studies need to work on its explicit mechanism.

NK cells exert its function on pathogens, tumor cells, stressed hepatocytes, and HSCs via the production of cytokines (IFN- $\gamma$, TNF- $\alpha$, IL-10, IL-12, IL-22, etc.) and cytotoxic molecules (granzyme B, Perforin, etc.) both in direct or indirect fashion [26]. The over-expressed NKG2A in hepatitis and HCC patients showed markedly reduction of IFN- $\gamma$ secretion. Moreover, the NKG2A blockade resulted with significant boosts of IFN- $\gamma$ production and interdependent of $\mathrm{NK}$ and $\mathrm{CD}^{+} \mathrm{T}$ cell functions to prevent in hepatitis and HCC patients $[44,45]$. Besides, NKG2A downregulation increases the anti-tumor activity of NK cells and infusions in a subset patient with HCC [46]. Human liver-derived $\mathrm{CXCR6}^{+}$NK cells are predominantly educated through NKG2A and show reduced cytokine production [47]. NKG2A downregulation enhanced NK cytotoxicity and accelerates effective treatment responses in patients with chronic myeloid leukemia [48]. Notably, IFN- $\gamma$ produced by NK cells plays predominant role during anti-viral [19], anti-fibrosis [49], and anti-tumor [50], anti-parasitic process [24]. And, its secretion is inhibited by over expression of TGF- $\beta$ and IL-10 and therefore related with immune tolerance [51]. High levels of plasma IL-10 is related with over expression of NKG2A and lead to decreased secretion of IFN-gamma and cytotoxicity [12]. In line with abovementioned results, treatment with antiNKG2A resulted with increased production of NK cells secreted IFN- $\gamma$ in vivo study [44]. Da-Zhong Shi reported the possible curative effect of IFN- $\gamma$ both in human and experimental study and indicated the importance of IFN- $\gamma$ during E. multilocularis infection [52]. Further, our results showed the significant reduction of regional levels of NK cell secreted IFN- $\gamma$ in E. multilocularis infection and negative correlation with NKG2A expression.

There are still some inherent limitations of current study should be stated. First, our results were based upon experimental model that might not be the best option but the result currently available. The failure to access commercialized antibody of NKG2A kept us from deeper understanding the possible role of it during $E$. multilocularis infection, however, this would be done in our future work in support to current findings.

\section{Conclusions}

Our study illustrated the significant reduction of liver NK cells population but obvious upregulation of NKG2A expression in E. multilocularis infected mice. Such opposite alteration might be related to the impaired production of INF- $\gamma$, as well as the disease progression with its potentiality in the immune tolerance milieu in infected liver. Further investigations should be made to identify the more explicit role of NKG2A in liver NK cells exhaustion, which would be very helpful to restoring NK cell related immunity against E. multilocularis infection.

\section{Additional files}

Additional file 1: Table S1. Fluorescent labeled antibodies for flowcytometry. (DOCX 16 kb)

Additional file 2: Figure S1. The decline in hepatic NK cells' functions in E. multilocularis infection. (PPTX $301 \mathrm{~kb}$ )

Additional file 3: Figure S2. . The expression of activated and inhibitory receptors on the hepatic NK cells in E. multilocularis infection. (PPTX $532 \mathrm{~kb}$ )

Additional file 4: Figure S3. The cytokine production of hepatic $\mathrm{NKG} 2 \mathrm{~A}^{+} \mathrm{NK}$ and NKG2D+ NK cells after E. multilocularis infection. (PPTX $566 \mathrm{~kb})$

\section{Abbreviations \\ ELRA: Ex vivo liver resection followed by autotransplantation technique

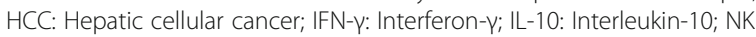 cells: Natural killer cells; NKG2A: Natural killer group 2, member A; NKG2D: Natural killer group 2, member D; PBMC: Peripheral blood mononuclear cell; PBS: Phosphate buffer saline; TGF- $\beta$ : Transforming growth factor- $\beta$; TNF-a: Tumor necrosis factor $-a$; $a-S M A$ : a smooth muscle actin}

\section{Acknowledgements}

The authors thank Clinical Institute of Xinjiang Medical University for providing research platform for this study and thank professor Dominique A. Vuitton for providing expertise.

\section{Authors' contributions}

HWen and YS conceived the whole study and revised the manuscript; TA interpreted all data and was responsible for data presentation; AAbulizi performed all experimental research in this study, collected and analyzed the data, drafted and revised the manuscript; $Z \mathrm{~L}$ and $\mathrm{CZ}$ participated in performing NK cell depletion experiment; AAini, HWang, LL, NZ was responsible for animal care and took part in some other experiments in this study; RL critically advised to study design and administratively provided research platform for this study; TT helped HWen revising the discussion section and was responsible for linguistic issues of this article; HWen approved for publication. All authors together have read and approved the manuscript.

\section{Funding}

National Natural Science Foundation of China (No. 81560098 to Yingmei Shao) and Xinjiang Uyghur Autonomous Region Key Laboratory Open Research Program (No. 2017D04004 to Tuerganaili Aji) financially supported this study from design to submission process, including: all experimental materials and animal purchase, animal fed costs, reagent and relevant laboratory chemical reagent costs, as well as students' remuneration who joined the study performance. All authors together declare that there was no other financial compete to disclose.

\section{Availability of data and materials}

The datasets used and/or analyzed during the current study available from the corresponding author on reasonable request. 


\section{Ethics approval and consent to participate}

All animals received humane care in compliance with the Medical Research Center's guidelines, and animal procedures were approved by the Animal Care and Use Committee and the Ethical Committee of First Affiliated Hospital of Xinjiang Medical University (Approval No. 20150225-134). All surgery was performed under chloral hydrate anesthesia, and all efforts were made to minimize suffering.

\section{Consent for publication}

Not applicable.

\section{Competing interests}

The authors declare that they have no competing interests.

\section{Author details}

${ }^{1}$ State Key Laboratory of Pathogenesis, Prevention and Treatment of High Incidence Diseases in Central Asia, Hepatobiliary \& Hydatid Disease Department, Digestive \& Vascular Surgery Center, First Affiliated Hospital of Xinjiang Medical University, Urumqi 830054, China. ${ }^{2}$ WHO Collaborating Center on Prevention and Management of Echinococcosis, First Affiliated Hospital of Xinjiang Medical University, Urumqi 830054, China. ${ }^{3}$ Xinjiang Key Laboratory of Fundamental Research on Echinococcosis, Clinical Medical Institute, First Affiliated Hospital of Xinjiang Medical University, Urumqi 830054, China. ${ }^{4}$ Department of Liver and Laparoscopic Surgery, Digestive \& Vascular Surgery Center, First Affiliated Hospital of Xinjiang Medical University, Urumai 830054, China.

\section{Received: 30 April 2019 Accepted: 27 August 2019}

Published online: 09 September 2019

\section{References}

1. Deplazes P, Rinaldi L, Alvarez Rojas CA, Torgerson PR, Harandi MF, Romig T, Antolova D, Schurer JM, Lahmar S, Cringoli G, et al. Global distribution of alveolar and cystic echinococcosis. Adv Parasitol. 2017:95:315-493.

2. Torgerson PR, Keller K, Magnotta M, Ragland N. The global burden of alveolar echinococcosis. PLoS Negl Trop Dis. 2010;4(6):e722

3. Aji T, Dong JH, Shao YM, Zhao JM, Li T, Tuxun T, Shalayiadang P, Ran B, Jiang TM, Zhang RQ, et al. Ex vivo liver resection and autotransplantation as alternative to allotransplantation for end-stage hepatic alveolar echinococcosis. J Hepatol. 2018;69(5):1037-46.

4. Vuitton DA, Zhou H, Bresson-Hadni S, Wang Q, Piarroux M, Raoul F, Giraudoux P. Epidemiology of alveolar echinococcosis with particular reference to China and Europe. Parasitology. 2003;127(Suppl):S87-107.

5. Brunetti E, Kern P, Vuitton DA. Expert consensus for the diagnosis and treatment of cystic and alveolar echinococcosis in humans. Acta Trop. 2010; 114(1):1-16

6. Wen H, Vuitton L, Tuxun T, Li J, Vuitton DA, Zhang W, DP MM. Echinococcosis: Advances in the 21st Century. Clin Microbiol Rev. 2019;32(2): $1-39$.

7. Wang J, Gottstein B. Immunoregulation in larval Echinococcus multilocularis infection. Parasite Immunol. 2016;38(3):182-92.

8. Vuitton DA, Gottstein B. Echinococcus multilocularis and its intermediate host: a model of parasite-host interplay. J Biomed Biotechnol. 2010;2010: 923193

9. Wang J, Goepfert C, Mueller N, Piersigilli A, Lin R, Wen H, Vuitton DA, Vuitton L, Mueller C, Gottstein B. Larval Echinococcus multilocularis infection reduces dextran sulphate sodium-induced colitis in mice by attenuating $T$ helper type 1/type 17-mediated immune reactions. Immunology. 2018; 154(1):76-88.

10. Wang J, Müller S, Lin R, Siffert M, Vuitton DA, Wen H, Gottstein B. Depletion of FoxP3(+) Tregs improves control of larval Echinococcus multilocularis infection by promoting co-stimulation and Th1/17 immunity. Immun Inflamm Dis. 2017:5(4):435-47.

11. Tuxun T, Apaer S, Ma HZ, Zhang H, Aierken A, Lin RY, Wen H. The potential role of Th9 cell related cytokine and transcription factors in patients with hepatic alveolar echinococcosis. J Immunol Res. 2015;2015:895416.

12. Zhang C, Shao Y, Yang S, Bi X, Li L, Wang H, Yang N, Li Z, Sun C, Lu G, et al. T-cell tolerance and exhaustion in the clearance of Echinococcus multilocularis: role of inoculum size in a quantitative hepatic experimental model. Sci Rep. 2017;7(1):11153.
13. Rehmann P, Grone A, Gottstein B, Sager H, Muller N, Vollm J, Bacciarini LN Alveolar echinococcosis in the zoological garden Basle. Schweizer Archiv Tierheilkunde. 2005;147(11):498-502.

14. Nono JK, Pletinckx K, Lutz MB, Brehm K. Excretory/secretory-products of Echinococcus multilocularis larvae induce apoptosis and tolerogenic properties in dendritic cells in vitro. PLoS Negl Trop Dis. 2012:6(2):e1516.

15. Webb LM, Tait Wojno ED. The role of rare innate immune cells in type 2 immune activation against parasitic helminths. Parasitology. 2017;144(10): 1288-301.

16. Bogdanos DP, Gao B, Gershwin ME. Liver immunology. Compr Physiol. 2013; 3(2):567-98

17. Bihl F, Pecheur J, Breart B, Poupon G, Cazareth J, Julia V, Glaichenhaus N, Braud VM. Primed antigen-specific CD4+ T cells are required for NK cell activation in vivo upon Leishmania major infection. J Immunol(Baltimore, Md : 1950). 2010:185(4):2174-81.

18. Parasa VR, Sikhamani R, Raja A. Effect of recombinant cytokines on the expression of natural killer cell receptors from patients with TB or/and HIV infection. PLoS One. 2012;7(6):e37448.

19. Rehermann B. Natural killer cells in viral hepatitis. Cell Mol Gastroenterol Hepatol. 2015;1(6):578-88.

20. Lorenzo-Herrero S, Lopez-Soto A, Sordo-Bahamonde C, Gonzalez-Rodriguez AP, Vitale M, Gonzalez S. NK Cell-Based Immunotherapy in Cancer Metastasis. Cancers. 2018;11(1):29.

21. Gigley JP. The diverse role of NK cells in immunity to toxoplasma gondii infection. PLoS Pathog. 2016;12(2):e1005396.

22. Wolf AS, Sherratt S, Riley EM. NK cells: uncertain allies against malaria. Front Immunol. 2017:8:212.

23. Messlinger $H$, Sebald $H$, Heger $L$, Dudziak D, Bogdan C, Schleicher U. Monocyte-derived signals activate human natural killer cells in response to Leishmania parasites. Front Immunol. 2018;9:24.

24. Chen AL, Qiu XY, Wang W, Zhou CL, Zeng X, Liu XJ, Qiu JF, Wang Y. The quantitative and functional changes of NK cells in mice infected with Angiostrongylus cantonensis. Parasitol Res. 2014;113(6):2087-94.

25. Hou X, Yu F, Man S, Huang D, Zhang Y, Liu M, Ren C, Shen J. Negative regulation of Schistosoma japonicum egg-induced liver fibrosis by natural killer cells. PLoS Negl Trop Dis. 2012:6(1):e1456.

26. Zheng M, Sun H, Tian Z. Natural killer cells in liver diseases. Front Med. 2018; 12(3):269-79.

27. Bellanger AP, Mougey V, Pallandre JR, Gbaguidi-Haore H, Godet Y, Millon L. Echinococcus multilocularis vesicular fluid inhibits activation and proliferation of natural killer cells. Folia Parasitol. 2017;64:029.

28. Yao $Y$, Yang W, Yang YQ, Ma HD, Lu FT, Li L, Tao YY, Tsuneyama K, Zhang W, Friedman S, et al. Distinct from its canonical effects, deletion of IL-12p40 induces cholangitis and fibrosis in interleukin-2Ralpha(-/-) mice. J Autoimmun. 2014:51:99-108.

29. Zhang C, Wang J, Lu G, Li J, Lu X, Mantion G, Vuitton DA, Wen H, Lin R. Hepatocyte proliferation/growth arrest balance in the liver of mice during $E$. multilocularis infection: a coordinated 3-stage course. PloS one. 2012;7(1): e30127.

30. Chiossone L, Chaix J, Fuseri N, Roth C, Vivier E, Walzer T. Maturation of mouse NK cells is a 4-stage developmental program. Blood. 2009;113(22): 5488-96.

31. Horowitz A, Stegmann KA, Riley EM. Activation of natural killer cells during microbial infections. Front Immunol. 2011;2:88

32. Guilmot A, Hermann E, Braud VM, Carlier Y, Truyens C. Natural killer cell responses to infections in early life. J Innate Immun. 2011;3(3):280-8.

33. Vivier $\mathrm{E}$, Tomasello $\mathrm{E}$, Baratin $\mathrm{M}$, Walzer T, Ugolini S. Functions of natural killer cells. Nat Immunol. 2008;9(5):503-10.

34. Bi J, Tian Z. NK Cell Exhaustion. Front Immunol. 2017:8:760.

35. Sultana MA, Du A, Carow B, Angbjär CM, Weidner JM, Kanatani S, Fuks JM, Muliaditan T, James J, Mansfield IO, et al. Downmodulation of Effector Functions in NK Cells upon Toxoplasma gondii Infection. Infect Immun. 2017:85(10):1-13.

36. Lieke T, Nylen S, Eidsmo L, Schmetz C, Berg L, Akuffo H. The interplay between Leishmania promastigotes and human natural killer cells in vitro leads to direct lysis of Leishmania by NK cells and modulation of NK cell activity by Leishmania promastigotes. Parasitology. 2011;138(14):1898-909.

37. Zhang S, Hue S, Sene D, Penfornis A, Bresson-Hadni S, Kantelip B, CaillatZucman S, Vuitton DA. Expression of major histocompatibility complex class I chain-related molecule a, NKG2D, and transforming growth factor-beta in the liver of humans with alveolar echinococcosis: new actors in the tolerance to parasites? J Infect Dis. 2008;197(9):1341-9. 
38. Peng H, Jiang X, Chen Y, Sojka DK, Wei H, Gao X, Sun R, Yokoyama WM, Tian Z. Liver-resident NK cells confer adaptive immunity in skin-contact inflammation. J Clin Invest. 2013;123(4):1444-56.

39. Liu Y, Abudounnasier G, Zhang T, Liu X, Wang Q, Yan Y, Ding J, Wen H, Yimiti D, Ma X. Increased expression of TGF-beta1 in correlation with liver fibrosis during Echinococcus granulosus infection in mice. Korean J Parasitol. 2016;54(4):519-25.

40. Wang J, Zhang C, Wei X, Blagosklonov O, Lv G, Lu X, Mantion G, Vuitton DA, Wen H, Lin R. TGF-beta and TGF-beta/Smad signaling in the interactions between Echinococcus multilocularis and its hosts. PLoS One. 2013;8(2):e55379.

41. Tuxun T, Ma HZ, Apaer S, Zhang H, Aierken A, Li YP, Lin RY, Zhao JM, Zhang $\mathrm{JH}$, Wen $\mathrm{H}$. Expression of toll-like receptors 2 and 4 and related cytokines in patients with hepatic cystic and alveolar echinococcosis. Mediat Inflamm. 2015;2015:632760.

42. Li F, Wei H, Gao Y, Xu L, Yin W, Sun R, Tian Z. Blocking the natural killer cell inhibitory receptor NKG2A increases activity of human natural killer cells and clears hepatitis B virus infection in mice. Gastroenterology. 2013;144(2): 392-401.

43. Jinushi M, Takehara T, Tatsumi T, Kanto T, Miyagi T, Suzuki T, Kanazawa Y, Hiramatsu N, Hayashi N. Negative regulation of NK cell activities by inhibitory receptor CD94/NKG2A leads to altered NK cell-induced modulation of dendritic cell functions in chronic hepatitis $C$ virus infection. J Immunol(Baltimore, Md : 1950). 2004;173(10):6072-81.

44. Andre P, Denis C, Soulas C, Bourbon-Caillet C, Lopez J, Arnoux T, Blery M, Bonnafous C, Gauthier L, Morel A, et al. Anti-NKG2A mAb is a checkpoint inhibitor that promotes anti-tumor immunity by unleashing both $\mathrm{T}$ and NK cells. Cell. 2018;175(7):1731-43 e1713.

45. Zhang C, Wang XM, Li SR, Twelkmeyer T, Wang WH, Zhang SY, Wang SF, Chen JZ, Jin X, Wu YZ, et al. NKG2A is a NK cell exhaustion checkpoint for HCV persistence. Nat Commun. 2019;10(1):1507.

46. Kamiya T, Seow SV, Wong D, Robinson M, Campana D. Blocking expression of inhibitory receptor NKG2A overcomes tumor resistance to NK cells. J Clin Invest. 2019:129(5):2094-106.

47. Lunemann S, Langeneckert AE, Martrus G, Hess LU, Salzberger W, Ziegler AE, Lobl SM, Poch T, Ravichandran G, Sauter J, et al. Human liver-derived CXCR6(+) NK cells are predominantly educated through NKG2A and show reduced cytokine production. J Leukoc Biol. 2019;105(6):1-10

48. Chang MC, Cheng HI, Hsu K, Hsu YN, Kao CW, Chang YF, Lim KH, Chen CG. NKG2A Down-regulation by Dasatinib enhances natural killer cytotoxicity and accelerates effective treatment responses in patients with chronic myeloid leukemia. Front Immunol. 2018;9:3152.

49. Shi J, Zhao J, Zhang X, Cheng Y, Hu J, Li Y, Zhao X, Shang Q, Sun Y, Tu B, et al. Activated hepatic stellate cells impair NK cell anti-fibrosis capacity through a TGF-beta-dependent emperipolesis in HBV cirrhotic patients. Sc Rep. 2017;7:44544.

50. Malmberg KJ, Levitsky V, Norell H, de Matos CT, Carlsten M, Schedvins K Rabbani H, Moretta A, Soderstrom K, Levitskaya J, et al. IFN-gamma protects short-term ovarian carcinoma cell lines from CTL lysis via a CD94/NKG2Adependent mechanism. J Clin Invest. 2002;1 10(10):1515-23.

51. Liaskou E, Wilson DV, Oo YH. Innate immune cells in liver inflammation. Mediat Inflamm. 2012;2012:949157.

52. Shi DZ, Li FR, Bartholomot B, Vuitton DA, Craig PS. Serum sIL-2R, TNF-alpha and IFN-gamma in alveolar echinococcosis. World I Gastroenterol. 2004; 10(24):3674-6.

\section{Publisher's Note}

Springer Nature remains neutral with regard to jurisdictional claims in published maps and institutional affiliations.

Ready to submit your research? Choose BMC and benefit from:
- fast, convenient online submission
- thorough peer review by experienced researchers in your field
- rapid publication on acceptance
- support for research data, including large and complex data types
- gold Open Access which fosters wider collaboration and increased citations
- maximum visibility for your research: over 100M website views per year
At BMC, research is always in progress.
Learn more biomedcentral.com/submissions

